
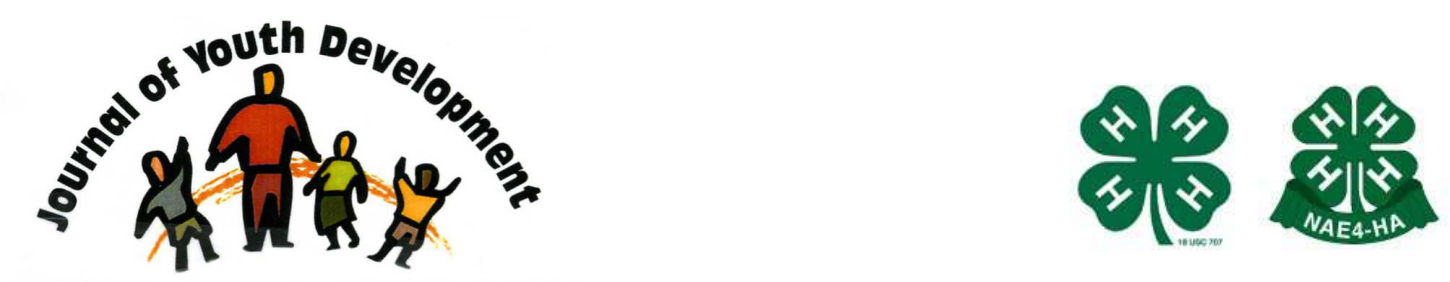

Bridging Research \& Practice

\title{
Building Capacity for Latino/Hispanic Volunteer Engagement
}

\author{
Sonia G. Morales Osegueda \\ Diversity Specialist \\ Agriculture Youth Development 4-H Faculty \\ Washington State University Extension \\ Renton, WA \\ sgmorales@wsu.edu
}




\title{
JOURNAL OF YOUTH DEVELOPMENT \\ bridging research and practice

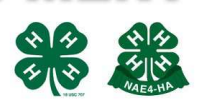

Volume 7, Number 3, Fall 2012

Article 120703PA003

\section{Building Capacity for Latino/Hispanic Volunteer Engagement}

\author{
Sonia G. Morales Osegueda \\ Washington State University Extension
}

\begin{abstract}
Hispanics have become the largest ethnic minority group in the United States. Within that population there are vast diversities of culture that vary not only by country of origin, but by the regions and ethnicities within those countries. Designing programs to attract the participants and meet the needs of Latinos and their families is essential to 4-H's future outreach program success. King County Extension Youth Development 4-H program has developed a program that provides volunteerism training based on awareness of the community that youth and adult participants serve. Results suggest that volunteer training helps participants become more prepared. They develop the knowledge and skills needed for planning, implementing a program, and applying their individual talents as well as mentoring strengths. This article describes how newly skilled Latinos participating in volunteerism training demonstrated and practiced what they learned at an elementary school in SeaTac, Washington.
\end{abstract}

\section{Introduction}

The 2010 Decennial Census counted 50.5 million Hispanics/Latinos in America, which become the largest ethnic group now constituting $16.3 \%$ of the total United States population (Lopez, \& Dockterman, 2011; United States Census of Bureau, 2011). Nowhere have these changes been more evident than in the state of Washington, where the Hispanic population is widely dispersed. The number of residents grew by 71 percent between 2000 and 2010. This group now composes 11 percent of the state's population, up from 7.5 percent in 2000 . In King County, Latinos comprise 8.9 percent of the population (Santjer, 2011; United States Census of Bureau, 2011).

Realizing the implication that those numbers represent in our increasingly multicultural society, many organizations seeking more meaningful connections would like to recruit more Latino volunteers and mentors (Hobbs, 2000). Latino leaders would increase volunteer ranks and build stronger collaborative bonds across communities and youth organizations. Their individual 
experiences would enrich the organization with cultural perspectives and the variety of their personal experiences (Naggy, 2011). Moreover, engaging volunteers is known to build awareness and community involvement by strengthening the collective capacity to solve their own problems (Morales, 2011b).

In American society many volunteer-based organizations have operated successfully in the homogeneous environments (Hobbs, 2000). Voluntary participation which has characterized so much of America in the past, is still seen as an integral part of the community (Fahrenthold, 2003; Gregory, Steinbring, \& Sousa, 2003). However, methods and approaches that have worked effectively in more homogenous settings may not be as useful in more diverse environments. Therefore, the future success of voluntary organizations will depend in large part on how different value systems can be incorporated into ongoing programs and how well we can help new groups of people with the acculturation process (Rodriguez, 1997).

With the increasing diversity and generational layers within the Latino community, most organizations face challenges to identify ways to diversify and expand programs in a manner comfortable to the cultural style of such communities. Valuing diversity in name and deed will allow organizations to recruit individuals with the multicultural skills and abilities necessary to create opportunities to expand benefits for volunteers and further strengthen programs they later deliver (Braker, Leno, Pratt, \& Grobe, 2000; Hobbs, 2000). For instance, material translated into, or published in Spanish might be utilized to address the needs of significantly diverse communities (Clutter, \& Nieto, 2000; Hoorman, 2002). This type of outreach makes it possible to accommodate language skills, cultural understanding and differences at implementing programs (Ellis, \& Noyes, 1990).

Successful efforts in recruitment and retaining Latino adults as volunteers will depend on the awareness of, and sensitivity to the cultural differences between the American culture and Latin American (Hobbs, 2007). Moreover, this will dictate the need for change in Extension program approaches. Extension personnel are increasingly becoming more capable of addressing the needs of a multicultural population (Hobbs, 2004). Reassuringly, the addition of new approaches does not mean the mission and goals of Extension are being superseded, but ultimately more productively transformed.

The need to expand youth development programs within diverse communities, while embracing their cultural sensitivities, makes it imperative that Extension work harder to enable volunteers from those communities. Developing a more aggressive volunteer recruitment effort will enhance and bring new challenges, while increasing the level of participation of Hispanic Americans as volunteers.

A study conducted by Sousa, Gregory, Campbell, Dasher, \& Snell, (2007) to explore successful activities that benefit the Latino community has shown that many of the participants were more comfortable with informal methods of helping. They explained that community members were more willing to get involved if there was a specific event that needed to be accomplished rather than an ongoing commitment. Offering opportunities to participate in special events and be part of a small group of friends and family working together may be a more effective way of promoting participation (Gregory, et al., 2006). The natural disposition to this kind of interaction should prompt opportunities for local leaders to develop programs that promote community vitality and collective learning. 
Latino engagement has become essential to developing programs that accommodate the needs of the community. It is therefore important for Extension programs to establish and strengthen relationships with Hispanic-American service agencies such as faith-based organizations, schools, and community centers which have worked to expand the number of diverse volunteers. This will create ways to increase, expand and develop Latino volunteers with the capacity to assume active roles in local programs to maintain and enrich the quality of community life (Hamilton, \& Hamilton, 2011; López, \& Safrit, 2001).

\section{Program Implementation}

Washington State University Extension, sets clear objectives in order to effectively serve diverse communities and families across the state. In response to engaging Latinos in volunteering opportunities, the King County 4-H Youth Development Program has created a multicultural program targeting topics that range from arts and crafts, to nutrition and health. The program also includes activities in mathematics and reading (Morales, 2011a). The program, which provides Latino youth and families with the necessary tools to enhance communication with the larger community, has been implemented in several locations such as community centers, churches, and schools, specifically targeting children in grades K-6.

The multicultural program focuses on bringing together urban youth and adults from diverse backgrounds and provides them the opportunity to work in a multicultural environment. It also offers a quality training that inspires youth ages 14-18 and parents to participate and become involved in community growth. The training places emphasis on youth development, skills development and relevant cultural activities that meet the needs of the local community and is particularly relevant to those with a Latino background. Additionally, learning opportunities are provided for participants in the areas of designing, organizing, and implementing a group program. Ultimately, the program offers an alternate route of participation in 4-H Youth Development, other than club leadership.

\section{Purpose and Objectives}

The purpose of this program is to recruit and engage youth and adults in volunteerism training. This process provides volunteers with knowledge and skills that will help them to perform specific tasks related to their assigned roles in a local project group. Nine Latino youth and eighteen adult program participants committed to work for a period of three weeks in the multicultural summer program with thirty-five elementary children in 2011 . The objectives were:

a) to provide volunteerism training to twenty-seven Latino youth and adults;

b) to provide individuals with the knowledge needed to understand youth and skills development; and

c) to provide the tools needed to plan and implement a summer program for young Latinos.

\section{Methods/Procedures}

King County Extension's 4-H Youth Development Program developed a partnership with Bow Lake Elementary School in SeaTac, WA which was interested in developing a multicultural program for 35 Latino children. King County 4-H Program also partnered with a Latino volunteer leader at the school who works closely with parents. Eighteen Latino adults including 
the volunteer leader and nine youth ages 14-18 participated in the volunteerism leadership training. The training lasted for eight hours and consisted of two parts (Appendix 1).

Part 1. The first part of the training provided new volunteers with a foundation of knowledge about the following subjects:

a) 4-H Full Value Contract: A full value contract is an agreement between group members that defines how they will communicate and treat one another. It establishes the ground rules on how participants will work together and communicate with each other even when there are disagreements within the group (Evertson, 2009).

b) The foundation of volunteerism: participants learn about volunteerism as an American tradition of giving and volunteering for the greater benefit of the larger community. They also learn the differences that exist in volunteerism practices in both the American and Latino cultures, and how they can become a part of the culture of volunteerism (Morales, 2010b).

c) Culture and diversity: participants learn the importance of involvement in cultural practice that may be reflected by cultural knowledge, understanding appreciation and accepting differences that exist among cultures (Morales, 2010a).

d) Ages and stages: focuses on understanding the developmental characteristics and tasks of youth from six to nineteen years of age. It explores the four basic developmental characteristics which are physical, social, emotional, and intellectual development of youth. (Levings, 2006; McFarland, \& Huebner, 2008; Texas 4-H \& Youth Development, 2011).

e) Experiential learning model: This learning model teaches life skills through the use of five steps - experience, share, process, generalize, and apply. Those steps can be summarized into three main processes; Do, Reflect, and Apply. This process engages the learners in all phases of the activity which encourages them to think more and work harder. This results in the ability to generalize this learning to new situations. (Diem, 2001; Evertson, 2009; Norman, \& Jordan, 2006; Townson, 2004).

Part 2. The second part of the volunteerism training focuses on planning, designing, and implementing a multicultural summer program. Activities were discussed and determined by volunteers and by the availability of resources. Lastly, volunteers were able to identify and assign roles and responsibilities to work in the summer program.

At the end of the training an open questionnaire with the following three questions was provided directly to the twenty seven participants (face to face). (1) Why did you participate in the volunteerism training? (2) Did the content of the training increase your knowledge about volunteers and/or program implementation? (3) How will you use what you learned?

The questionnaire was written in Spanish, translated into English, and back translated into Spanish to establish its validity and for analysis purposes. The data were analyzed using frequencies and percentages.

\section{Findings and Discussions}

1. Why did you participate in the volunteerism training? Of the 18 adults ( $67 \%$ of the total population) participating in the volunteerism training, $14(78 \%)$ had never before attended formal leadership volunteerism training. They affirmed that they gained expertise that would help to develop skills, knowledge, and abilities needed to more effectively get involved in their 
children's activities at school, after school, and during summer programs. Moreover, adult volunteers commented that they enjoyed being with others and learning from each other. Additionally, most volunteers said that the Latino community has many needs, and Latinos need to get more involved in volunteerism programs. Furthermore, personal trust relationships play a big role in how and where people in the Latino community choose to volunteer or lead (Sousa, Gregory, Campbell, Dasher, \& Snell, (2007). Most of the participants mentioned that they generally participate in service when they receive an invitation by someone they know. Lastly, they generally showed a disposition to spend more time volunteering at local schools.

Nine youth participants, 14 to 18 years of age (33\% of the total population), cited personal interests, such as developing leadership skills, that will help when working with children and others, meeting new friends, and staying engaged. Youth also mentioned that they normally volunteer at Bow Lake Elementary School. They engage children in different activities while their parents attend school events that provide them an opportunity to meet at least once per month.

2. Did the content of the training increase your knowledge about volunteers, leadership skills development, and program implementation strategies? Twenty- two participants (81\%) affirmed they increased their knowledge about volunteering. They pointed out that before the training they did not realize how important it was that they work on events in the community, school, church, and with family. However, after the training they were able to appreciate their skills, and what they could offer to the family and immediate community. Moreover, the collaboration allowed participants to discuss and identify specific individual tasks that will give them the opportunity to apply the knowledge and skills learned. Youth participants stated that they feel motivated to continue developing skills. Additionally, five adult participants mentioned that they already spend time helping at school. Parents acknowledged that school teachers have recognized and appreciated the time and skills they contribute, and their dedication to the development of their younger generations.

3. How will you use what you learned? Twenty-five participants (93\%) said they want to put acquired knowledge of working with children into practice during the summer program. Participants mentioned that being part of group strategic program planning made them feel confident that they will be able to contribute significantly to program implementation. Overall, new volunteers expressed their inclination to invite their neighbors to be involved in volunteering activities at school and in the community.

\section{Conclusions and Recommendations}

The interest that Latinos demonstrated given volunteering opportunities has shown that the set of tools necessary for planning and implementing a multicultural program with culturally or context-sensitive activities was pivotal. This event offered volunteers the opportunity to explore the challenges of a variety of leadership roles. Further involvement of youth and adult Latino volunteers engaged with children provided the opportunity to keep volunteers motivated, and to practice their skills responsibly at all levels of participation.

An increase in the number of parent volunteers partnering with schools was observed through the summer program. Parent volunteers had an absolute influence on the quality of relationships with their children. They were able to experience how much their children accomplished while engaging in the multicultural program. Moreover, parents passed their traditions through cultural activities, meeting people with similar interest, culture and language. 
Finally, they enjoyed activities with which they felt comfortable while they were volunteering to support their children and their school and community friends.

Volunteering as a teenager has an impact, not only on the chance that an individual will volunteer as an adult, but also on the formation of ideological motivators (Fahrenthold, 2003). Therefore, it is recommended to recruit young individuals that will provide a significant pool of potential volunteers for inclusion in development programs, especially during summer when most students have limited opportunities for employment. In addition to making a positive contribution to their community, youth volunteers also developed skills that are essential to their future success as adults.

The lack of either a fluency in English or a deep understanding of Euro-American culture makes it necessary in many cases to provide separate training for Latino volunteers (Hobbs, 2004). Therefore, developing quality volunteer and leadership training programs delivered in Spanish will build immense potential for growth in the Latino community. The approach has been known to provide space and opportunity for the creation of programs that support skills development and building awareness. From our own observations and follow-up, communities became stronger because of the volunteering opportunities and general interest in building relationship to nurture new volunteers who are willing to serve their community.

It is recommended that youth development professionals across the country continue building local relationships, promoting leadership programs, while attracting non-mainstream volunteers. It will in turn support the expansion of 4-H Youth Development programs that benefit families by offering volunteerism opportunities with a multi-cultural component.

Lastly, this program is a positive model that can also be replicated by other Non-Extension youth-serving organizations interested in promoting, recruiting and developing people for volunteerism training. It has the possibility of providing participants the opportunity to understand cultural aspects of any diverse community as they to develop their interest in volunteerism to its highest potential.

\section{References}

Braker, M.J., Leno, J.R., Pratt, C.C., \& Grobe, D. (2000). Oregon Extension volunteers: partners in action. Journal of Extension [On-line], 38(2) Article 2RIB3. Retrieved from http://www.joe.org/joe/2000april/rb3.html.

Clutter, A.W., \& Nieto, R.D. (2000). Understanding the Hispanic culture. Ohio State University Fact sheet [On-line], HYG 5237-00. Retrieved from http://ohioline.osu.edu/hygcact/5000/5237.html.

Diem, K.G. (2001). Leader training series: Learn by doing the 4-H way. The State University of New Jersey Rutgers Cooperative Extension. Retrieved from http://njaes.rutgers.edu/pubs/pdfs/4h/e148/447-454.pdf

Ellis, S., \& Noyes, C.K. (1990). By the people: A history of Americans as volunteers. San Francisco: CA: Jossey-Bass Publishers. 
Evertson, E.G. (2009). New Mexico Military Institute ropes course facilitator training manual (level 1), 24-27. Retrieved from

http://www.nmmi.edu/academics/leadership/documents/fullnmmiropescoursetrainingmanualv10 rvsdsept09bwf-b.pdf.

Fahrenthold, L. (2003). Family volunteering and youth engagement in the non-profit sector: An analysis of benefits. The University of Texas at Austin. Retrieved from

http://www.serviceleader.org/volunteers/familyvolunteering

Gregory, P., Camarillo, J., Campbell, D.C., Dasher, S., King, N., Mann, M., et al. (2006).

Learning from Latino community efforts. Journal of Extension [On-line], 44(3) Article 3FEA3.

Retrieved from http://www.joe.org/joe/2006june/a3.php.

Gregory P., Steinbring, I.J., \& Sousa, C.M. (2003). Voluntary community involvement of Latinos: A literature review. University of California Cooperative Extension, DANR. Retrieved from http://latinomi.wikispaces.com/file/view/Gregory et.al. VoluntaryCommInvol 2003.

Hamilton H.C., \& Hamilton, A. (2011). Recruiting and retaining a diverse, culturally responsive guardian ad Litem volunteer pool in Durham County. The Sanford School of Public Policy program master's projects. Duke University, North Carolina. Retrieved from http://dukespace.lib.duke.edu/dspace/handle/10161/3579.

Hobbs, B. (2007). Cultural responsive practice: The Key to engaging Latinos as adult volunteers. The International Journal of Volunteer Administration, 24 (6), 26-34.

Hobbs, B. (2004). Latino outreach programs: Why they need to be different. Journal of Extension [On-line], 42(4) Article 4COM1. Retrieved from http://www.joe.org/joe/2004august/comm1.php.

Hobbs, B. (2000). Recruiting and supporting Latino volunteers. A Pacific Northwest Extension publication. 4H Youth Development, Oregon State University, 7-8.

Hoorman, J.J. (2002). Engaging minority and culturally diverse audience. Journal of Extension, $40(4), 1-4$.

Levings, J. (2006). How kids develop. Iowa 4-H Volunteer. Iowa State University Extension, V1950902. Retrieved from https://www.extension.iastate.edu/4H/Documents/VI950902FAgesStages.PDF.

Lopez, M.H., \& Dockterman, D. (2011, May 26). U.S. Hispanic country of origin counts for nations, top 30 metropolitan areas. Pew Research Center for the People \& the Press. Retrieved from http://www.pewhispanic.org/2011/05/26/us-hispanic-country-of-origin-counts-for-nationtop-30-metropolitan-areas/.

López, B., \& Safrit, R.D. (2001). Hispanic American volunteering. Journal of Extension [Online], 39(6) Article 6RIB2. Retrieved from http://www.joe.org/joe/2001december/rb2.php.

McFarland, M., \& Huebner, A. (2008). Characteristics and development tasks of youth ages 619. In Preparing the youth development professional. 4-H Army Youth Development, USDA, and Kansas State University, 53-67. Retrieved from http://www.4-hmilitarypartnerships.org/p.aspx?tabid=117. 
Morales, S. (2011a). 4-H multicultural summer program: A model to develop lifelong skills. In 4-H Publications \& Projects. Washington State University Extension 4-H Youth Development Program, EM2778, 37. http://4h.wsu.edu/profdev/eao.html.

Morales, S. (2011b). Volunteer study involving the Latino community. (Unpublished article). Washington State University Extension. http://4h.wsu.edu/profdev/eao.html.

Morales, S.G. (2010a). Cultura y diversidad. Unpublished [Power Point slides]. Washington State University Extension King County.

http://4h.wsu.edu/profdev/documents/Culturaydiversidad.pdf.

Morales, S.G. (2010b). El Voluntariado en la comunidad latina. Unpublished [Power Point slides]. Washington State University Extension King County.

http://4h.wsu.edu/profdev/documents/training voluntariado.pdf.

Naggy, J. (2011). Recruiting volunteers. The Community Tool Box. University of Kansas.

Retrieved from http://ctb.ku.edu/en/tablecontents/sub section main 1107.aspx.

Norman, M.N., \& Jordan, J.C. (2006). Using an experiential model in 4-H. University of Florida IFAS Extension. Fact sheet [on-line], 4-HSFS101.10. Retrieved from https://edis.ifas.ufl.edu/4h243.

Rodriguez, S. (1997). Diversity and volunteerism: Deriving advantage from difference. The Journal of Volunteer Administration, Volume XV (3), 18-20.

Santjer, M. (2011, February 23). Census 2010: A look at Washington State. Renton Patch. Retrieved from http://renton.patch.com/articles/census-2010-a-look-at-washington-state\#photo-4749608.

Sousa, C.M., Gregory, P., Campbell, D.C., Dasher, S., \& Snell, D. (2007). Recommendations for working in partnership with Latino communities: A guide for public agencies and other social service practitioners. University of California. ANR Publication 8206, 1-9.

Texas 4-H \& Youth Development Strengthening Clubs Initiative Team. (2011). Ages \& stages of youth development. Agri Life Extension Texas A\&M System. Retrieved from

http://texas4-

h.tamu.edu/files/2011/12/club ed training agenda4 topic1 Ages Stages PPNotes for Agent.p df.

Townson, L. (2004). Experiential learning. University of New Hampshire Cooperative Extension. Retrieved from http://extension.unh.edu/resources/files/Resource000157 Rep170.pdf.

United States Census Bureau. (2011). The Hispanic population: 2010. Retrieved from http://www.census.gov/prod/cen2010/briefs/c2010br-04.pdf.

(C) Copyright of Journal of Youth Development Bridging Research and Practice. Content may not be copied or emailed to multiple sites or posted to a listserv without copyright holder's express written permission. However, users may print, download or email articles for individual use. 


\section{Appendix 1}

Youth and Adults Volunteer Training Outline

\section{Part I.}

Welcome/Introductions

Icebreaker activities

Expectations for the program

Training objectives/our responsibilities

4-H Full Value Contract

BREAK

Foundation of Volunteerism

Culture and Diversity

Characteristics of Youth (ages and stages)

Experiential Learning Model and practice

\section{Part II:}

Planning, designing, and implement a program

Example of activities

Arts \& Crafts, music, dance

Etiquette, Food and Nutrition

Math and reading

Skills development

Communication, Self-esteem, Leadership, Team work, etc.

Reflection/Discussion

Question and Answer

Evaluation

Adjourn 